\title{
Long-Term Fluticasone Propionate/Formoterol Fumarate Combination Therapy Is Associated with a Low Incidence of Severe Asthma Exacerbations
}

\author{
Alberto Papi, MD, FERS, ${ }^{1}$ Adel H. Mansur, PhD, FRCP, Tetyana Pertseva, MD, PhD, ${ }^{3}$ \\ Kirsten Kaiser, MD, PhD, Tammy Mclver, MSc, CStat, CSci, \\ Birgit Grothe, Dipl Biol, and Sanjeeva Dissanayake, MRCP, MSc ${ }^{6}$
}

\begin{abstract}
Background: A primary goal of asthma management is the reduction of exacerbation risk. We assessed the occurrence of oral corticosteroid-requiring exacerbations (OCS exacerbations) with long-term fluticasone/formoterol therapy, and compared it with the occurrence of similar events reported with other inhaled corticosteroid/long acting $\beta_{2}$-agonist (ICS/LABA) combinations.

Methods: The occurrence of OCS exacerbations was assessed in two open-label trials of fixed-dose fluticasone/ formoterol administered for between 26 to 60 weeks in adults and adolescents with asthma. The incidence of OCS exacerbations with fluticasone/formoterol was compared with those reported in three recent Cochrane meta-analyses of other ICS/LABAs.

Results: The pooled incidence of OCS exacerbations with long-term fluticasone/formoterol was $2.1 \%$ (95\% CI: 1.1 , $3.2 \%, n / N=16 / 752$ ). In only two of the nineteen treatment arms summarized by Cochrane did OCS exacerbation incidence approximate that seen in the two fluticasone/formoterol trials (single-inhaler fluticasone/salmeterol [2.9\%]; separate inhaler budesonide, beclometasone, or flunisolide plus formoterol [3.4\%]). In Lasserson's review the pooled incidence of OCS exacerbations for single-inhaler combinations was 9.5\% (95\% CI: 8.4, 10.6\%; $n / N=239 / 2516)$ for fluticasone/salmeterol, and 10.6\% (95\% CI: 9.3, 11.8\%; $n / N=257 / 2433)$ for budesonide/formoterol. In Ducharme's and Chauhan's meta-analyses (primarily incorporating separate inhaler combinations [fluticasone, budesonide, beclometasone, or flunisolide plus salmeterol or formoterol]), the pooled incidences of OCS exacerbations were $16.0 \%$ (95\% CI: $14.2,17.8 \%, n / N=258 / 1615)$ and $16.7 \%$ (95\% CI: $14.9,18.5, n / N=275 / 1643)$, respectively.

Conclusions: The incidence of exacerbations in two fixed-dose fluticasone/formoterol studies was low and less than in the majority of comparable published studies involving other ICS/LABA combinations. This difference could not be readily explained by differences in features of the respective studies and may be related to the favorable pharmacological/mechanistic characteristics of the constituent components fluticasone and formoterol compared to other drugs in their respective classes.
\end{abstract}

Key words: asthma, fluticasone propionate, fluticasone/formoterol, flutiform ${ }^{\circledR}$, formoterol, severe exacerbations

\footnotetext{
${ }^{1}$ Research Centre on Asthma and COPD, University of Ferrara, Ferrara, Italy.

${ }^{2}$ Chest Research Institute, Birmingham Heartlands Hospital, Birmingham, United Kingdom.

${ }^{3}$ Dnipropetrovsk State Medical Academy, Dnipropetrovsk, Ukraine.

${ }^{4}$ Medicinal and Regulatory Development, Skyepharma AG, Muttenz, Switzerland.

${ }^{5}$ Clinical Data Management and Statistics, and ${ }^{6}$ Medical Science-Respiratory, Mundipharma Research Limited, Cambridge, United Kingdom.

(C) Alberto Papi, et al., 2016. Published by Mary Ann Liebert, Inc. This Open Access article is distributed under the terms of the Creative Commons Attribution Noncommercial License (http://creativecommons.org/licenses/by-nc/4.0/) which permits any noncommercial use, distribution, and reproduction in any medium, provided the original author(s) and the source are credited.
} 


\section{Introduction}

$\mathbf{T}$ HE REDUCTION OF EXACERBATION RISK is a primary goal of asthma management. ${ }^{(1,2)}$ Prior exacerbations, ${ }^{(3,4)}$ poor asthma control, ${ }^{(4,5)}$ activity limitation, ${ }^{(4)}$ treatment compliance, ${ }^{(6)}$ lower forced expiratory volume in the first second $\left(\mathrm{FEV}_{1}\right){ }^{(3,7-9)}$ and allergic rhinitis ${ }^{(10,11)}$ are predictors of future exacerbation risk. Asthma exacerbations impair quality of life, cause significant debilitation, and in rare cases may lead to death. Exacerbations are associated with absences from work or school and increased healthcare costs. ${ }^{(12-14)}$

Although there is no standardized definition of an asthma exacerbation, there is agreement that asthma exacerbations requiring oral corticosteroids are intuitively meaningful, ${ }^{(1,2,15)}$ and this simple, clinically relevant outcome has routinely been evaluated in most asthma trials, allowing between-trial comparisons. ${ }^{(15-20)}$

Combination inhaled corticosteroid (ICS)/long-acting $\beta_{2^{-}}$ agonists (LABAs) reduce the risk of exacerbations compared to ICS alone ${ }^{(16,21,22)}$ and are recommended where asthma is not controlled with ICS monotherapy. A combination of fluticasone propionate (fluticasone) and formoterol fumarate (formoterol) in an HFA pMDI inhaler (fluticasone/ formoterol; flutiform $^{\circledR}$ ) has been evaluated in a comprehensive programme of randomized controlled clinical trials. ${ }^{(23-29)}$ In addition, the long-term tolerability and safety of fluticasone/formoterol has been demonstrated in two openlabel, fixed-dose clinical trials of 60 weeks (Study 1) ${ }^{(30)}$ and 26-52 weeks (Study 2) ${ }^{(31)}$, respectively. Here we assess the occurrence of exacerbations requiring oral corticosteroid therapy in those two studies. To contextualize these data, we assessed the occurrence of similar events reported with other ICS/LABAs in three recent Cochrane meta-analyses, ${ }^{(22,32,33)}$ drawn in turn from a total of twelve long-term fixed-dose studies in broadly similar patient populations.

\section{Materials and Methods}

The occurrence of oral corticosteroid-requiring exacerbations (OCS exacerbations) was assessed in Studies $1^{(30)}$ and $2^{(31)}$ of fluticasone/formoterol given at a fixed dose in 752 asthmatic patients aged $\geq 12$ years. The incidence of OCS exacerbations with fluticasone/formoterol was compared with those reported in the three most recent Cochrane metaanalyses detailing the efficacy and safety of other fixed dose ICS/LABA combinations in asthma. The meta-analyses did not include ICS/LABA studies where doses could be varied dependent upon treatment response or those employing "SMART" or "MART" maintenance and reliever strategies.

Factors known to predict or modify asthma exacerbation risk, based on consistent evidence from the published literature, were examined with the relevant data from each trial extracted and checked by two authors (SD and BG). Where the requisite data was not available from at least a third of the Cochrane studies (e.g., baseline eosinophil levels) the corresponding data were not summarized, given the difficulty in drawing any meaningful conclusions thereof.

\section{Long-term fluticasone/formoterol studies}

Both fluticasone/formoterol studies were of an open-label, long-term, multicentre design and enrolled two distinct populations of patients.
Study $1^{(30)}$ (a follow-on study) assessed the long-term safety and efficacy of fluticasone/formoterol $250 / 10 \mu \mathrm{g}$ twice daily (b.i.d.) over 60 weeks in 280 patients who had completed an earlier 12 -week phase 3 trial $^{(34)}$ within the previous 24 weeks. Patients had $40 \%-80 \%$ predicted $\mathrm{FEV}_{1}$, and were using $\leq 500 \mu \mathrm{g}$ fluticasone or equivalent/day [Study 1: NCT00747318/EudraCT 2008-002460-34; preceding 12week trial: NCT00649025/EudraCT 2007-005653-37].

Key exclusion criteria for the parent study were: a history of life-threatening asthma, hospitalization or intubation for asthma within the past year, an emergency room (ER) visit for asthma or OCS for asthma in the preceding 3 months, the use of omalizumab within 6 months or leukotriene receptor antagonists within 1 week, and a smoking history within the preceding 12 months. Asthma medications other than study treatment were prohibited during the study and patients were discontinued if they required systemic corticosteroid treatment for an asthma exacerbation.

In the parent study, patients received fluticasone/formoterol $250 / 10 \mu \mathrm{g}$ b.i.d. $(N=146)$ or fluticasone $250 \mu \mathrm{g}$ b.i.d. $(N=292) ; 392$ patients $(89.5 \%)$ completed and 46 patients discontinued, of these, 4 patients (1 fluticasone/ formoterol, 3 fluticasone) discontinued due to asthma exacerbations, and 16 (1 fluticasone/formoterol and 15 fluticasone) due to loss of asthma control. A total of 280 patients continued into the follow-on study (i.e. Study 1).

Study $2^{(31)}$ evaluated the long-term safety of fluticasone/ formoterol $100 / 10 \mu \mathrm{g}$ or $250 / 10 \mu \mathrm{g}$ b.i.d. in 472 patients with $40 \%-85 \%$ predicted $\mathrm{FEV}_{1}$ and using $\leq 500 \mu \mathrm{g} /$ day fluticasone or equivalent (allocation to fluticasone/formoterol dose group was dependent upon the patient's pre-study ICS dose). Key exclusion criteria and prohibited concomitant medications were very similar to Study 1; however, in Study 2 patients could only enter the study with uncontrolled asthma and concomitant antimuscarinics were not specifically precluded. As in Study 1, the use of systemic corticosteroids for worsening asthma led to discontinuation from the study. The first 80 patients in each dose group received treatment for 12 months. Subsequent patients were treated for 6 months (NCT00394121/EudraCT 2005-003518-14).

For the main analysis, patients in Studies 1 and 2 were considered to have an "OCS exacerbation" if they had an asthma exacerbation that was treated with an oral, intramuscular, or intravenous corticosteroid for asthma: this allowed a like-for-like comparison with OCS exacerbation frequency as reported in the three Cochrane meta-analyses. A second definition of "respiratory exacerbations" was employed as a sensitivity analysis: patients were deemed to have a respiratory exacerbation if they received an oral, intramuscular, or intravenous corticosteroid for any respiratory illness. This definition was primarily intended to identify potentially miscoded OCS exacerbations. Patients captured by either definition who required hospital management were identified.

\section{Compliance with ethics}

Study 1 and Study 2 were conducted in accordance with the Declaration of Helsinki and International Conference on Harmonisation Good Clinical Practice guidelines, and were approved by the relevant independent ethics committees. All patients provided written informed consent. 


\section{Other ICS and LABA combination therapies}

Data on the incidence of OCS exacerbations with other combinations of an ICS and LABA were obtained from three recent Cochrane reviews (Ducharme et al.; ${ }^{(22)}$ Lasserson et al.; ${ }^{(32)}$ Chauhan and Ducharme $\left.{ }^{(33)}\right)$, selected as they were the most recent, relevant meta-analyses of fixed dose ICS/LABA combination therapy in asthma that included specific analyses of OCS exacerbations. From the Cochrane reviews we focused only on studies of patients aged $\geq 12$ years and only on studies of $>16$ weeks to ensure comparability with the fluticasone/formoterol studies. The primary outcome measure in all three Cochrane metaanalyses was the number of patients with one or more exacerbations requiring oral steroids (i.e., the incidence of OCS exacerbations).

The meta-analysis by Lasserson et al. ${ }^{(32)}$ estimated the relative effects of fixed-dose single-inhaler fluticasone/ salmeterol and budesonide/formoterol in five head-to-head long-term studies. OCS exacerbations were reported in four of the five studies (Aalbers et al., ${ }^{(35)}$ Busse et al., ${ }^{(36)}$ COMPASS [Kuna et al.], ${ }^{(37)}$ EXCEL [Dahl et al.. $\left.{ }^{(38)}\right)$. The four studies included 4949 patients, and each compared regular maintenance treatment with budesonide/formoterol $400 / 12 \mu \mathrm{g}$ b.i.d. with fluticasone/salmeterol $250 / 50 \mu \mathrm{g} /$ day (Table 1). Notably, the Lasserson studies were of somewhat shorter duration (24 or 28 weeks) than the fluticasone/ formoterol studies (26/52 weeks or 60 weeks).

The meta-analysis by Ducharme et al. ${ }^{(22)}$ compared fixed dose ICS plus LABA versus the same fixed dose of ICS alone in patients with asthma insufficiently controlled on ICS monotherapy. Five long-term studies (duration 24 to 52 weeks) from this Cochrane review (Pauwels et al. [FACET], ${ }^{(16)}$ O'Byrne et al. [OPTIMA], ${ }^{(18)}$ Aubier et al., ${ }^{(39)}$ Fitzgerald et al., ${ }^{(40)}$ and van der Molen et al. ${ }^{(41)}$ ) including 1615 patients, reported OCS exacerbations and are presented here. The studies all involved separate inhaler ICS/ LABA combinations (fluticasone + salmeterol, budesonide + formoterol, beclometasone + formoterol, and flunisolide + formoterol); Aubier et al. also evaluated a single-inhaler ICS/LABA (fluticasone/salmeterol) (Table 1). O'Byrne et al. ${ }^{(18)}$ and Pauwels et al. ${ }^{(16)}$ both evaluated two dose levels in their respective studies.

Chauhan and Ducharme's meta-analysis ${ }^{(33)}$ compared the addition of a LABA versus that of a leukotriene receptor agonist to the treatment regimen of asthmatics who remained symptomatic despite regular ICS. There were three long-term studies summarized in this review (Bjermer et al., ${ }^{(42)}$ Ilowite et al., ${ }^{(43)}$ and Price et al. ${ }^{(44)}$ ), including 1655 patients overall, which reported OCS exacerbations. The studies by Bjermer et al. ${ }^{(42)}$ and Ilowite et al. ${ }^{(43)}$ used separate inhaler ICS/LABA combinations (fluticasone + salmeterol), whilst the study by Price et al. ${ }^{(44)}$ allowed a range of separate or single inhaler ICS/LABA combinations (beclometasone, budesonide or fluticasone + salmeterol or formoterol or budesonide/formoterol or fluticasone/salmeterol) (Table 1).

Key entry criteria for the studies described above are summarized in Table 2 and were broadly comparable with patients' requirement for step-up to ICS/LABA ascertained in all but one case (FACET). Only the COMPASS study specifically recruited patients with a history of recent ex- acerbations ( $\geq 1$ in the previous $1-12$ months). All other studies excluded patients with a recent history of exacerbations, although the exact criteria varied from study to study. Studies 1 and 2 and the EXCEL study excluded patients with exacerbations in the preceding 3 months, while Aalbers et al., Busse et al., COMPASS, van der Molen et al., Bjermer et al., and Ilowite et al. all excluded patients with exacerbations within 1 month of study entry.

In the FACET study only very frequent exacerbators (3 or more courses of OCS or hospitalization due to asthma in the 6 months before study entry) were excluded. Patients in the study by Price et al., were excluded if they were experiencing an acute asthma exacerbation or had used systemic corticosteroids within 2 weeks of study entry. Fitzgerald et al. excluded patients who had had an exacerbation requiring an emergency room visit within 3 months of study entry. The studies reported by Aubier et al. and the OPTIMA study did not specify any inclusion/exclusion criteria regarding prior asthma exacerbations or recent systemic corticosteroid use.

There was some variation in baseline ICS doses: the two fluticasone/formoterol studies, the COMPASS study, and those of Aalbers et al. and Busse et al. imposed an upper limit for enrolment of 500-600 $\mu \mathrm{g}$ fluticasone propionateequivalents (FP-e)/day. In the OPTIMA study, patients were ICS-naive or on a low dose of $\leq 200 \mu \mathrm{g}$ FP-e/day. Somewhat higher screening doses of up to 800 to $1000 \mu \mathrm{g}$ FP-e/day were permitted in the remaining studies (Table 2).

Patients in most studies had uncontrolled symptoms at baseline, defined as the use of rescue medication and/or the presence of asthma symptoms during the run-in period (Table 2). The exceptions were fluticasone/formoterol Study 1 , which mandated uncontrolled symptoms at the start of the previous 12-week double-blind study, but not at the start of the 60 week extension study, and the FACET study, which required that randomized patients had stable asthma.

Following enrollment, only two of the studies mandated treatment with oral steroids for specific exacerbation criteria: the FACET study in case of a $>30 \%$ decrease from baseline peak expiratory flow rate (PEFR) for 2 consecutive days (as well as if deemed necessary by the investigator for clinical need) and van der Molen et al., where PEFR decreased by $>20 \%$ from baseline for 2 consecutive days.

Studies 1 and 2 were conducted across different territories (Study 1; Central, South and North America and Eastern Europe: Study 2; Eastern and Western Europe). Of the Cochrane studies, eight were performed in Europe and/or North America (one study also included Israel), whilst the countries in which four studies were undertaken were not specified (Table 1).

\section{Data analysis}

The incidence of OCS exacerbations (main analysis) and respiratory exacerbations (sensitivity analysis) for the fluticasone/formoterol studies was calculated by dividing the number of patients with at least one exacerbation event by the total number of patients in the studies, and the $95 \%$ confidence interval (CI) was calculated. A similar approach was used to calculate the pooled incidence of OCS exacerbations for fixed-dose fluticasone/salmeterol and budesonide/salmeterol for the studies included from Lasserson 


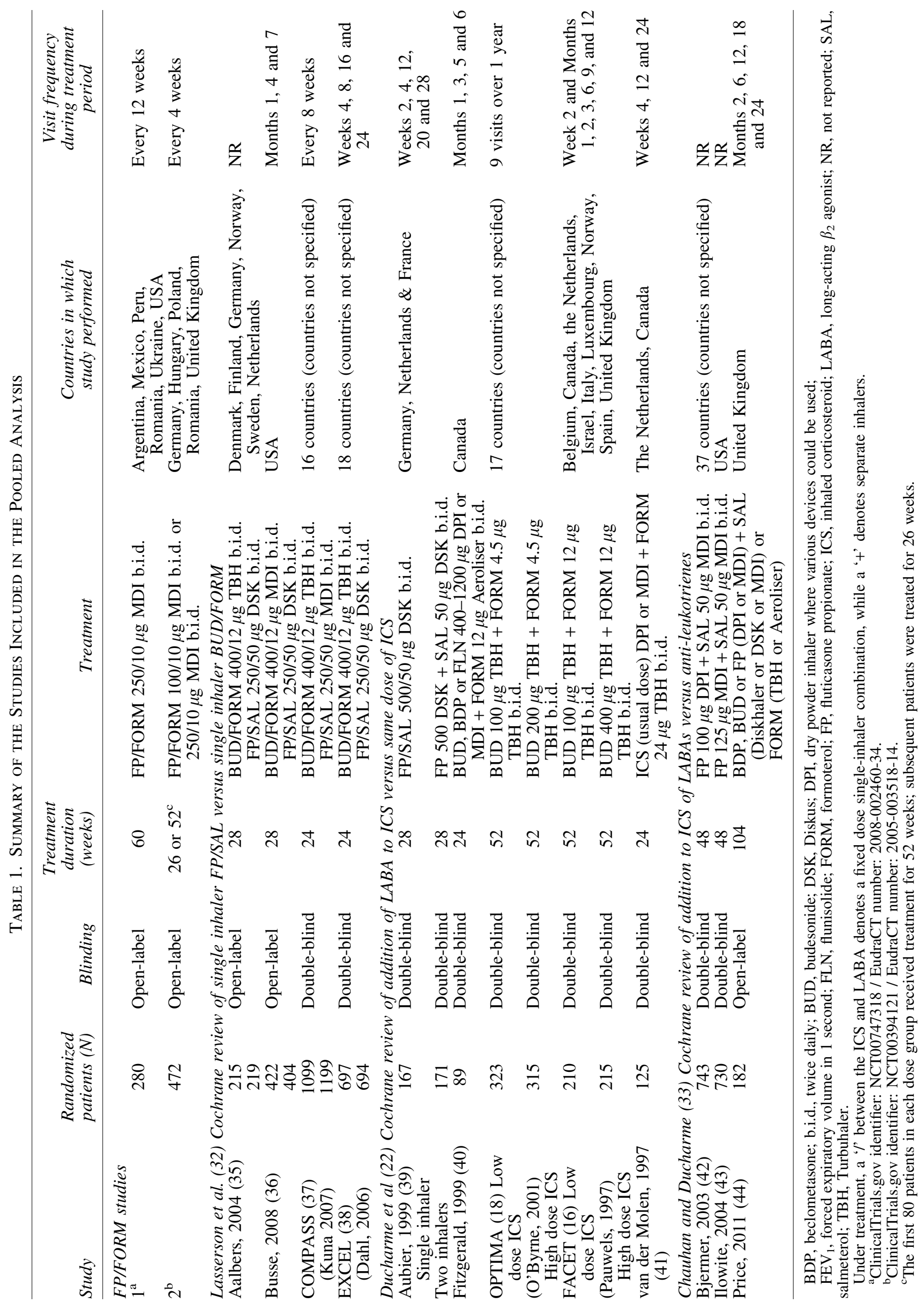




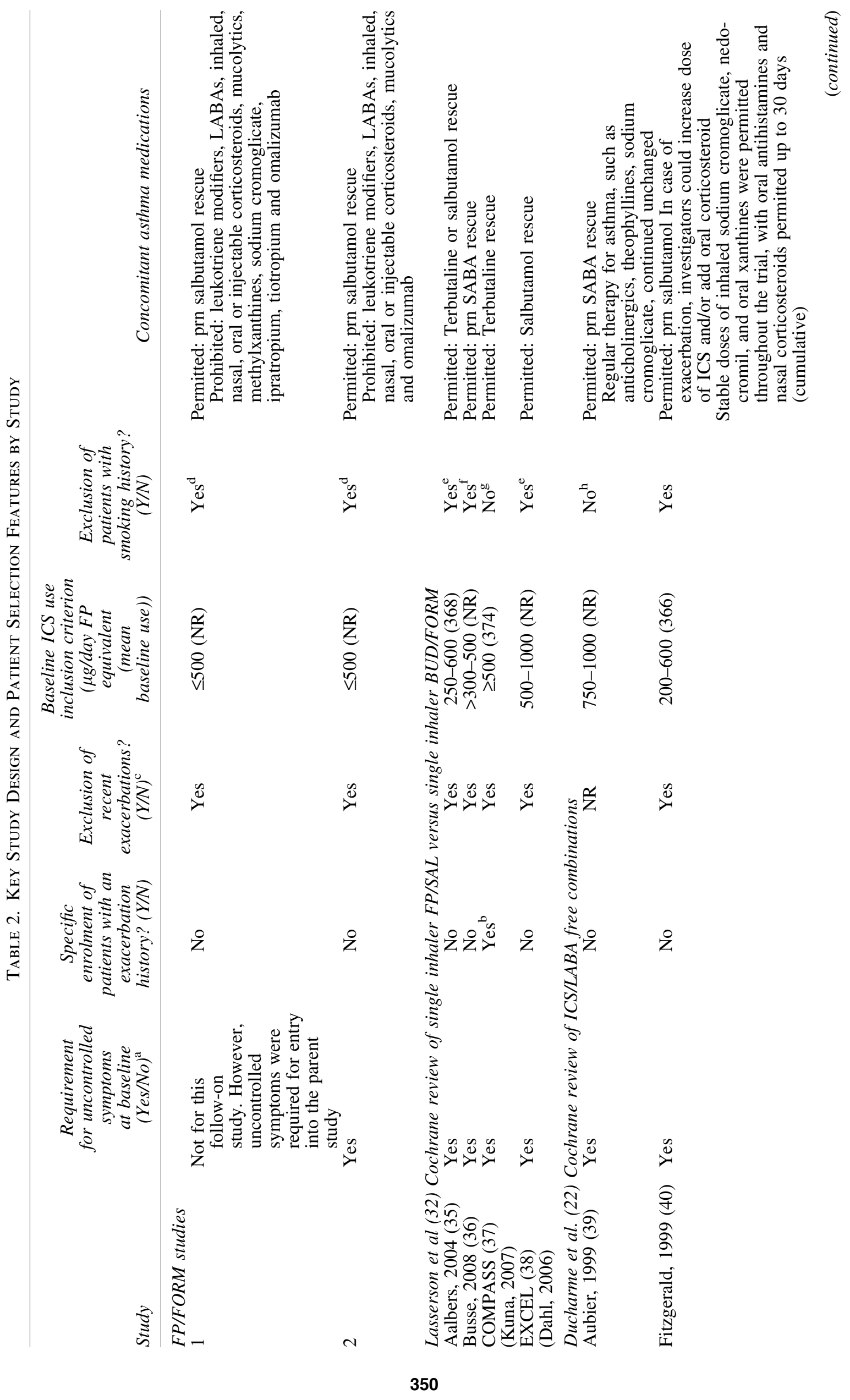




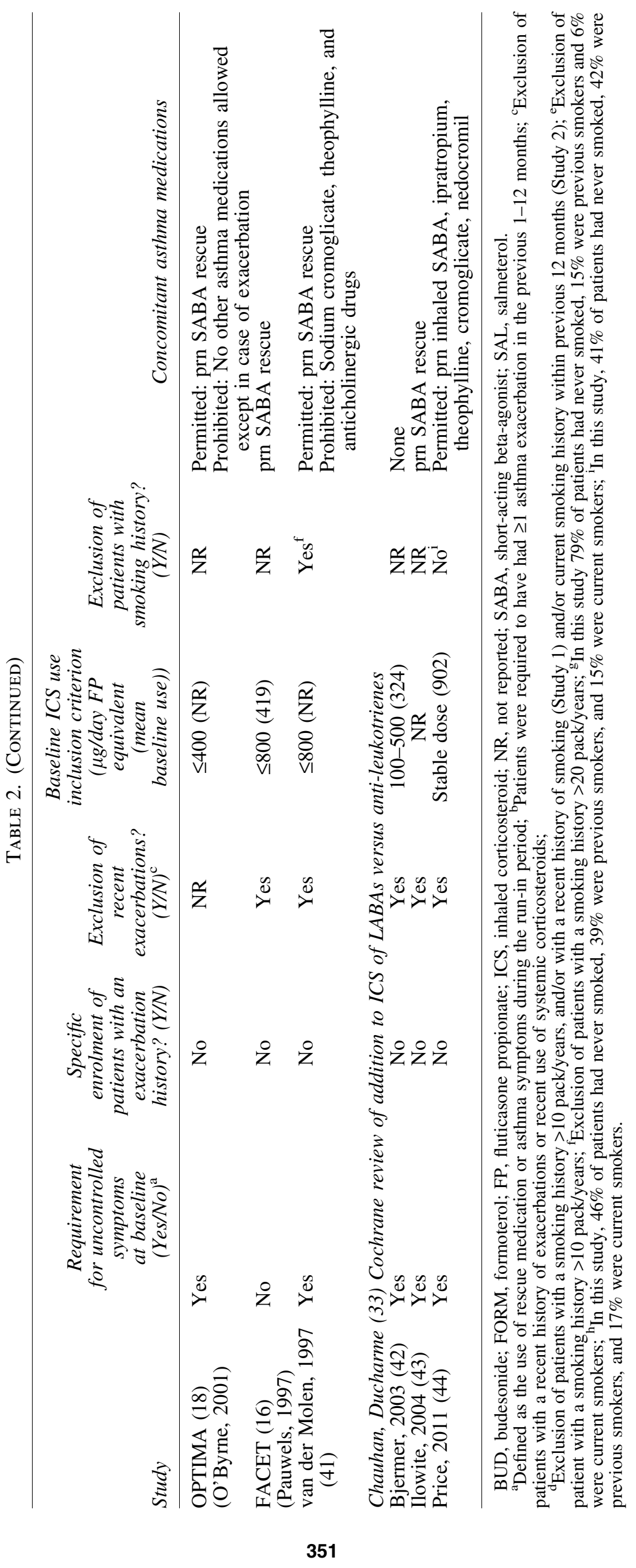


et al., and for the ICS and LABA combinations included from Ducharme et al. and Chauhan and Ducharme.

\section{Results}

\section{Baseline characteristics of patients}

Patient characteristics in the 12 Cochrane studies were broadly similar to those in the fluticasone/formoterol studies (Table 3). The mean age was 42-43 years in Studies 1 and 2, and 36-50 years for those from the Cochrane analyses. Mean $\mathrm{FEV}_{1} \%$ predicted was $67 \%-73 \%$ in Studies 1 and 2, and similar in 10 out of the 12 Cochrane studies $(68 \%$ $79 \%$ ), but somewhat higher in the study by Aalbers et al. and the OPTIMA study (84\%-87\%). Limited ethnicity data were available but, where detailed, patients were predominantly white. Whereas in the fluticasone/formoterol studies very few black patients $(0.4 \%-2.1 \%)$ were enrolled, as in studies by Bjermer et al. and Price et al., higher proportions were enrolled in two studies performed solely at U.S. centers (Busse et al., Ilowite et al.) (Table 3).

\section{Treatment adherence}

In both fluticasone/formoterol studies, adherence (assessed via patient diary cards and dose counter review) was high: $98 \%$ and $95 \%$ of subjects in Study 1 and 2, respectively, took at least $70 \%$ of their medication. Adherence data were available for 5 of the 11 Cochrane-summarized studies. ${ }^{(35-37,39,44)}$ High levels of adherence were seen in 4 of these studies: mean treatment compliance was $\geq 94 \%$ in Aubier's and Aalbers' studies, whilst $\geq 93 \%$ of subjects in Busse et al. and COMPASS reported taking at least $80 \%$ of their study medication. By contrast, in Price et al.'s real

Table 3. Baseline Characteristics of Patients by Study

\begin{tabular}{|c|c|c|c|c|c|}
\hline Study & $\begin{array}{l}\text { Mean } \\
\text { age }\end{array}$ & $\begin{array}{c}\text { Gender } \\
(\% \text { male:female })\end{array}$ & Ethnicity & $\begin{array}{c}F E V_{1} \\
\% \text { predicted }\end{array}$ & Reversibility (\%) \\
\hline
\end{tabular}

FP/FORM studies

$35: 65$

White $74.6 \%$

67

NR

Black $2.1 \%$

Asian $0.4 \%$

Hispanic $19.6 \%$

Other $3.2 \%$

2

$42 \quad 46: 54$

White $98.9 \%$

73

Black $0.4 \%$

Asian $0.6 \%$

Lasserson et al (32) Cochrane review of single inhaler FP/SAL versus single inhaler BUD/FORM

Aalbers, 2004 (35) BUD/FORM

$46-45 \cdot 55$

FP/SAL

Busse, 2008 (36) BUD/FORM

$46 \quad 49: 51$

NR

$\mathrm{NR}$

$34: 66$

White $82.0 \%$

84

Black $13.8 \%$

NR

Other $4.2 \%$

FP/SAL

39

43:57

White $84.0 \%$

Black 12.3\%

Other $3.7 \%$

COMPASS (37) BUD/FORM

$\begin{array}{ll}38 & 41: 59 \\ 38 & 43: 57 \\ 47 & 41: 59 \\ 46 & 44: 56\end{array}$

NR

NR

NR

NR

Ducharme et al (22) Cochrane review of ICS/LABA free combinations

Aubier, 1999 (39) Single inhaler $\quad 46 \quad 57: 43 \quad$ NR

Separate inhalers

$\begin{array}{ll}48 & 50: 50 \\ 36 & 53: 47 \\ 37 & 55: 55\end{array}$

Fitzgerald, 1999 (40)

OPTIMA (18) Low dose ICS

(O’Byrne, 2001) High dose ICS

FACET (16) Low dose ICS

(Pauwels, 1997) High dose ICS

van der Molen, 1997 (41)

45:55

$37 \quad 41: 59$

$41 \quad 50: 50$

$42 \quad 47: 53$

$41 \quad 49: 51$

NR

NR

NR

NR

NR

NR

$\mathrm{NR}$

73

Chauhan, Ducharme (33) Cochrane review of addition to ICS of LABAs versus anti-leukotrienes

Bjermer, 2003 (42)

$41 \quad 45: 55$

White $77.4 \%$

Black $0.5 \%$

Asian $7.4 \%$

Other $14.7 \%$

Ilowite, 2004 (43)

38

$37: 63$

White $85.6 \%$

Black 7.7\%

Hispanic 5.1\%

Price, 2011 (44)

$50 \quad 39: 61$

White $98 \%$

Other $2 \%$

85

79

78

73
73
79
79

73
73
79

79

86

86
87

76

76

68

73

74

NR

NR

NR

25

23

24

20

16

18

NR

NR

NR

NR

NR

25

19

NR

NR 


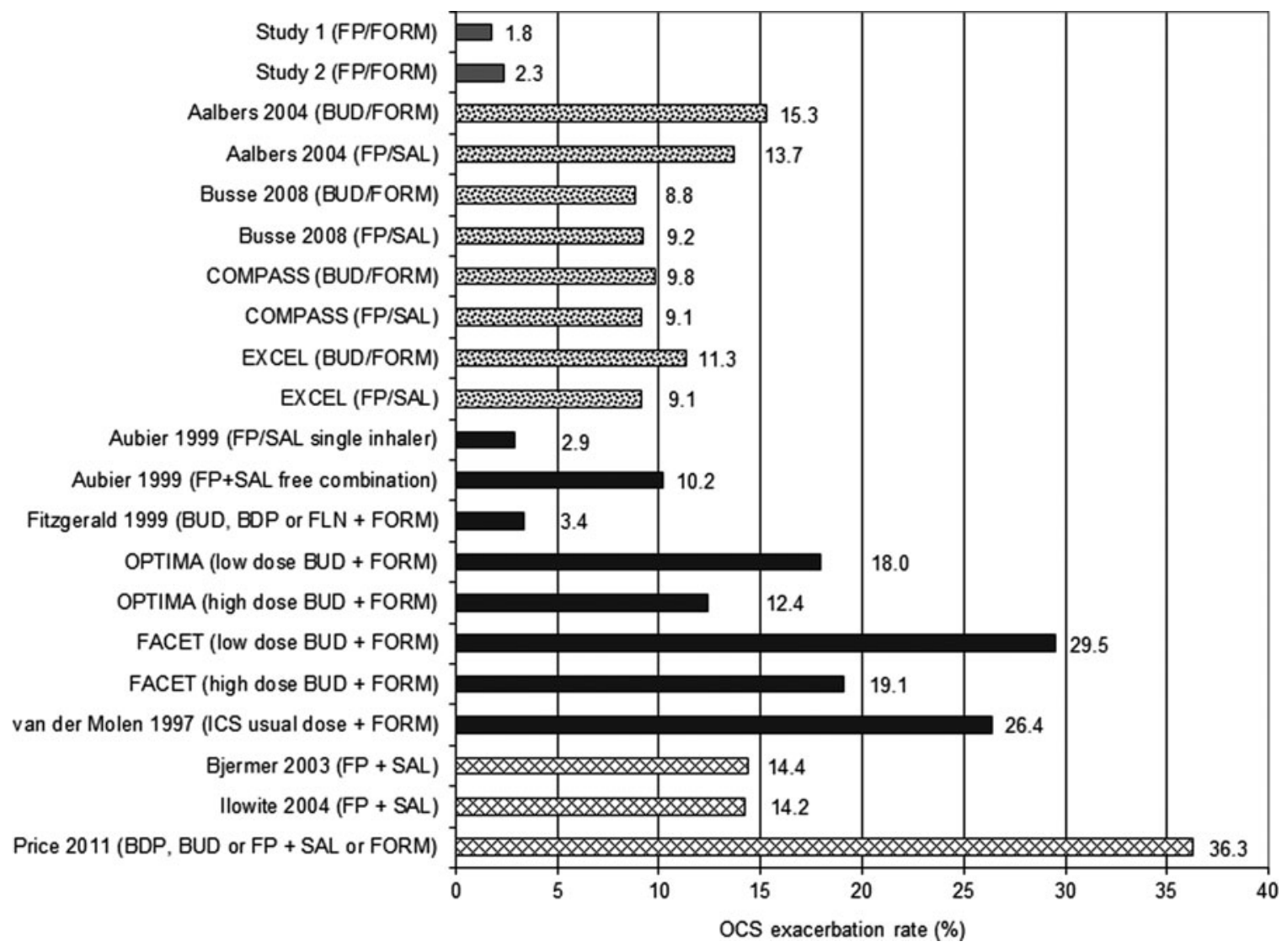

FIG. 1. OCS exacerbation incidences for individual studies of ICS/LABA combinations. ICS/LABA OCS exacerbation rates are for studies 1 and 2, and in the individual studies as reported in the Cochrane metaanalyses by Lasserson et al. ${ }^{(32)}$ Ducharme et al., ${ }^{(2)}$ and Chauhan and Ducharme. ${ }^{(33)}$ BDP, beclometasone; BUD, budesonide; FLN, flunisolide; FORM, formoterol; FP, fluticasone propionate; SAL, salmeterol.

world study, adherence (based on prescriptions issued) with LABA was only $46 \%$ and with ICS only $64 \%$.

\section{Incidence of exacerbations with fluticasone/formoterol}

Fluticasone/formoterol was associated with a similar, low incidence of OCS exacerbations in both studies (Fig. 1 and Table 4). The OCS exacerbation rate was $1.8 \%$ (95\% CI: $0.2,3.3 \%, n / N=5 / 280$ ) in Study 1 and $2.3 \%$ (95\% CI: 1.0 ,
$3.7 \%, n / N=11 / 472$ ) in Study 2. The pooled incidence of OCS exacerbations with long-term fluticasone/formoterol therapy was $2.1 \%(95 \% \mathrm{CI}: 1.1,3.2 \%, n / N=16 / 752)$.

The incidence of respiratory exacerbations (sensitivity analysis, including patients who received corticosteroids for any respiratory illness) was slightly higher: $2.9 \%$ of patients in Study 1 (95\% CI: 9.1, 4.8\%, $n / N=8 / 280)$ and $3.0 \%$ of patients in Study 2 (95\% CI: 1.4, 4.5\%, $n / N=14 / 472)$. The pooled respiratory exacerbation rate was $2.9 \%$ (95\% CI: $1.7,4.1 \%$,

Table 4. Long-Term Pooled OCS Exacerbation Rates with ICS/LABA Combinations*

\begin{tabular}{|c|c|c|c|}
\hline \multirow[b]{2}{*}{ ICS/LABA combination } & \multicolumn{3}{|c|}{ OCS exacerbation rate } \\
\hline & $\mathrm{n} / \mathrm{N}$ & $\%$ & $95 \%$ confidence interval \\
\hline Fluticasone/formoterol $^{\mathrm{a}}$ & $16 / 752$ & 2.1 & $1.1,3.2$ \\
\hline Fluticasone/formoterol $^{\mathrm{b}}$ & $22 / 752$ & 2.9 & $1.7,4.1$ \\
\hline Fluticasone/salmeterol [Lasserson, 2011 (32)] & $239 / 2516$ & 9.5 & $8.4,10.6$ \\
\hline Budesonide/formoterol [Lasserson, 2011 (32)] & $257 / 2433$ & 10.6 & $9.3,11.8$ \\
\hline ICS/LABA combinations [Ducharme, 2010 (22)] & $258 / 1615$ & 16.0 & $14.2,17.8$ \\
\hline ICS/LABA combinations [Chauhan, 2014 (33)] & $275 / 1643$ & 16.7 & $14.9,18.5$ \\
\hline
\end{tabular}

*Derived from fluticasone/formoterol studies and meta-analyses by Lasserson et al., 2011, Ducharme et al., 2010, and Chauhan and Ducharme, 2014.

OCS exacerbation, oral corticosteroid-requiring exacerbation.

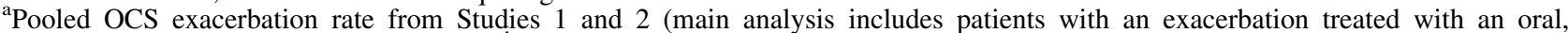
intramuscular, or intravenous corticosteroid); ${ }^{\mathrm{b}}$ Pooled severe exacerbation rate from Studies 1 and 2 (sensitivity analysis includes patients treated with oral, intramuscular, or intravenous corticosteroid for any respiratory illness). 
$n / N=22 / 752$ ), and the pooled hospitalization rate due to OCS exacerbations was $0.1 \%$ (95\% CI: $0,0.4 \%, n / N=1 / 752)$.

\section{Incidence of exacerbations with other ICS/LABA combinations}

The pooled incidence of OCS exacerbations from the four studies reported by Lasserson et al. was higher than that observed for fluticasone/formoterol at $9.5 \%$ (95\% CI: 8.4, $10.6 \% ; n / N=239 / 2516)$ for single-inhaler fluticasone/salmeterol (250/50 $\mu \mathrm{g}$ b.i.d.), and 10.6\% (95\% CI: 9.3, 11.8\%; $n / N=257 / 2433$ ) for single-inhaler budesonide/formoterol (400/12 $\mu \mathrm{g}$ b.i.d.) (Table 4). Variation in the incidence of OCS exacerbations was relatively low, ranging from $9.1 \%$ to $13.7 \%$ for budesonide/formoterol, and from $8.8 \%$ to $15.3 \%$ for fluticasone/salmeterol (Fig. 1).

For the ICS and LABA combinations in the five studies from Ducharme et al., the pooled incidence of OCS exacerbations was also notably higher than that seen with fluticasone/formoterol at $16.0 \%$ (95\% CI: 14.2, 17.8\%, $n / N=258 /$ 1615, Table 4). Across the five studies, the incidence of OCS exacerbations varied considerably (range: $2.9 \%$ to $29.5 \%$ ) and was greater than $10 \%$ in four of five studies (Fig. 1). Two studies (OPTIMA and FACET) assessed two dose levels of budesonide in conjunction with formoterol; in both studies, fewer OCS exacerbations were seen in the high dose group than in the low dose group (12.4\% vs. $18.0 \%$ and $19.1 \%$ vs. $29.5 \%$, respectively). OCS exacerbations resulting in hospitalization were reported for ICS/LABA combinations in the Aubier et al., FACET, and van der Molen et al. studies, with an average hospitalization rate of $0.5 \%(n / N=4 / 888)$.

The pooled incidence of OCS exacerbations for the ICS and LABA combinations in the three studies from Chauhan and Ducharme's Cochrane review ${ }^{(33)}$ was very similar to that from the Ducharme et al., ${ }^{(22)}$ at $16.7 \%$ (95\% CI: 14.9 , $18.5, n / N=275 / 1643$, Table 4). OCS exacerbation rates were more than 2-fold higher in the study by Price et al. $(36.3 \%$, Fig. 1) compared with the studies by Bjermer et al. (14.4\%) and Ilowite et al. (14.2\%). Exacerbations resulting in hospitalization were reported for $0.7 \%$ of patients $(n / N=5 / 718)$ receiving fluticasone + salmeterol free combination in the Ilowite et al. study. Hospitalization rates were not reported by Bjermer et al. or Price et al.

\section{Discussion}

Long-term fixed dose fluticasone/formoterol therapy was associated with a low incidence of OCS exacerbations in two separate studies: The pooled incidence of exacerbations in 752 patients was only $2.1 \%$ (95\% CIs $1.1 \%, 3.2 \%$ ) following a mean of 10 months treatment. A sensitivity analysis of "respiratory" exacerbations, which included any respiratory events treated with a systemic corticosteroid including those not reported as asthma exacerbations, produced similar results (pooled incidence 2.9\% [95\% CIs $1.7 \%, 4.1 \%])$.

The difference in OCS exacerbation incidence between the fluticasone/formoterol studies versus those reviewed by the Cochrane collaboration was surprising; a low incidence of exacerbations similar to that noted in the two fluticasone/ formoterol studies was only reported by Aubier et al. ${ }^{(39)}$ (for one of two arms in that study, single inhaler fluticasone/ salmeterol) and by Fitzgerald et al. ${ }^{(40)}$ (formoterol added to budesonide, beclometasone or flunisolide) from amongst 19 available datasets (Fig. 1). To better understand why such cross-trial differences might have been observed, we assessed key aspects of all studies with the potential to influence the occurrence of exacerbations.

Only one "real world" study was included amongst all those we reviewed, that of Price and co-workers. ${ }^{(4)}$ Inclusion criteria were less restrictive than in the other studies assessed, with no requirement for patients to exhibit bronchodilator reversibility criterion or demonstrate correct inhaler technique prior to enrollment, nor exclusion of patients with significant co-morbidity or smoking history, and no restriction on concomitant medications. This study was associated with a considerably higher incidence of exacerbations on ICS/LABA treatment $(36.3 \%)$ compared to all other studies we reviewed. This clearly suggests that the observed difference in exacerbation incidence is largely due to patient selection and the minimally interventional, "real life" nature of the study, likely allied to a prolonged study duration of 24 months and low rates of real world treatment adherence. The data of Price et al. are therefore of limited relevance to the fluticasone/formoterol data, hence the remainder of this discussion focuses primarily on the other 11 published studies (and 18 associated treatment arms).

Prior exacerbations are the strongest independent predictor of future exacerbation risk. ${ }^{(4,5,45)}$ In patients with asthma of varying severities, an exacerbation at baseline approximately trebles the odds of having an exacerbation at 1 year. ${ }^{(4,45)}$ Most of the ICS/LABA studies we reviewed clearly detailed enrollment criteria with respect to prior exacerbations. Only the COMPASS study specifically recruited a population with a prior history of exacerbations, hence this design difference was not the basis for the exacerbation incidence difference between the fluticasone/ formoterol and other studies reported. Interestingly, the incidence of OCS exacerbations in COMPASS was very similar to those in several of the other studies assessed.

All studies (including COMPASS) excluded patients with "recent" exacerbations, although studies differed in the length of time that patients had to be exacerbation-free prior to enrolment and in terms of the exact description of excluded exacerbations. Theoretically these differences might have impacted on exacerbation incidence during each trial if, for example, temporal clustering of exacerbations occurs in asthma in a similar manner to that described in COPD $^{(46)}$ (albeit this has not, to our knowledge, been described in asthma).

However, although the fluticasone/formoterol and EXCEL studies shared similar (3-month) exacerbation-free periods pre-study, the respective incidences of exacerbations clearly differed between these two studies $(2.1 \%$ [fluticasone/formoterol] versus $9.5 \%$ [fluticasone/salmeterol] and $10.6 \%$ [budesonide/formoterol]). Furthermore the incidence of exacerbations in EXCEL with both fluticasone/salmeterol and budesonide/formoterol was similar to those observed for these single inhaler combinations in COMPASS, and the studies of Busse et al. and Aalbers et al. (which each stipulated a 1 month exacerbation-free period). Thus there was no clear relationship between the exacerbation-free interval and subsequent exacerbation incidence in our review.

One study in which the exacerbation exclusion criterion employed does appear to be pertinent is FACET. Pauwels 
et al. only excluded very frequent exacerbators ( 3 or more OCS exacerbations within the past 6 months) from study participation. Note that FACET was one of only two studies (alongside van der Molen et al.) that stipulated that OCS should be instituted when reductions in PEFR of a certain magnitude were observed. These two studies reported the highest incidence of exacerbations across all those assessed (excluding Price's "real-world" study). Thus OCS treatment criteria based on PEFR would appear to explain, at least in part, the much greater exacerbation incidences in FACET and van der Molen's studies than in our own. In FACET, however, OCS could also be instituted based on clinical need, and $73 \%$ of OCS exacerbations were a result of clinical need rather a drop in PEFR. ${ }^{(47)}$ Hence, treatment criteria alone do not explain the high exacerbation incidence in FACET. The recruitment of all but the most frequent exacerbators into this study therefore appears to be the most likely cause of the high exacerbation incidence subsequently observed.

Lung function impairment is another of the most consistent, independent predictors of future exacerbation risk. $^{(3,4,8,9,45)}$ For example, Osborne and colleagues ${ }^{(8)}$ reported a relative risk for acute care of 2.43 in asthmatics with $\mathrm{FEV}_{1} 60 \%-80 \%$ predicted compared to those with $\mathrm{FEV}_{1}>80 \%$ predicted. Similar results were reported in a Dutch asthma cohort. ${ }^{(9)}$ Given these observations it is interesting that mean lung function in the two fluticasone/ formoterol studies (67\% and $73 \%$, respectively) was towards the lower end of the spectrum compared to the other studies assessed. van der Molen et al. reported a mean baseline of $68 \%$ predicted $\mathrm{FEV}_{1}$, whilst COMPASS and Aubier's study reported baseline values of $73 \%$ predicted $\mathrm{FEV}_{1}$. In the other studies reviewed, mean baseline lung function ranged from $76 \%$ to $87 \%$ predicted $\mathrm{FEV}_{1}$. Thus the degree of lung function impairment in the fluticasone/ formoterol studies does not explain the low exacerbation incidences subsequently seen, although it may have contributed to the high exacerbation incidence noted in van der Molen's study (in addition to the PEFR criteria stipulating when OCS should be instituted).

Another factor associated with the occurrence of exacerbations is uncontrolled disease. ${ }^{(4,5,45)}$ To simplify matters, given the use of different baseline descriptors of symptomatology, we categorized studies as either mandating or not mandating symptomatic disease as an enrollment criterion. Only two studies did not mandate the enrollment of symptomatic patients: fluticasone/formoterol Study 1 and FACET. Given that the incidences of OCS exacerbations in fluticasone/formoterol Studies 1 and 2 were very similar (1.8\% and $2.3 \%$, respectively), an enrollment criterion specifying symptomatic disease did not appear to influence the subsequent reporting of OCS exacerbations-possibly because the parent study to Study 1 did include a "symptomatic disease" inclusion criterion. Furthermore it is noteworthy that in FACET, despite the enrollment of patients with stable disease at baseline, the OCS exacerbation incidence $(19.1 \%$ and $29.5 \%$ on high and low dose budesonide + formoterol, respectively) was amongst the highest across all the studies assessed (Fig. 1). Overall, therefore, differences in baseline symptomatology did not appear to explain the lower incidence of exacerbations in the fluticasone/formoterol versus other studies.
The territories in which the studies were undertaken were reviewed, as the management and reporting of exacerbations may conceivably vary in different countries, resulting in regional differences in exacerbation incidence in a manner similar to that observed for COPD. ${ }^{(48)}$ Despite similar exacerbation incidences seen therein, the two fluticasone/formoterol studies were conducted across different territories. Unfortunately four of the published studies we examined did not detail the countries in which they were undertaken. However, from the available data no clear trends could be discerned to suggest that regional differences played a major role in influencing the occurrence of exacerbations observed.

ICS dose at study entry, a plausible surrogate for disease severity and/or treatment response ${ }^{(49)}$ was also examined. Broadly speaking, two study groups were evident: those where patients were on $\leq 500-600 \mu \mathrm{g}$ FP-e/day (which included both fluticasone/formoterol studies) and those in which $\leq 800-1000 \mu \mathrm{g}$ FP-e/day was allowed. Although very few studies presented the actual ICS dose at study entry, for those which did, the highest exacerbation incidences were seen in FACET and van der Molen's studies, both of which fell into the higher dose ICS category.

However, the dose entry criteria were not necessarily an indicator of actual ICS dose levels at study entry; the mean pre-study ICS dose in Aalbers' study (ICS entry criterion 250-600 FP-e) was $368 \mu \mathrm{g} /$ day, whereas in FACET an ICS entry criterion of $\leq 800 \mu \mathrm{g}$ FP-e resulted in a mean baseline ICS dose of $419 \mu \mathrm{g} / \mathrm{day}$. The high exacerbation incidences in the FACET and van der Molen studies may therefore be related to other aspects of their respective study designs, as discussed above, rather than prior ICS dose as a surrogate for disease severity.

Ethnicity was examined as exacerbations are more frequent in African American asthmatics than their white counterparts, even when concomitant medications ${ }^{(50)}$ and socioeconomic factors ${ }^{(51)}$ are adjusted for. Whilst ethnicity data were limited, it is relevant that in two Cochrane studies (Busse et al. and Ilowite et al.) higher proportions of black patients were enrolled $(7.7 \%-13.8 \%)$ than in the fluticasone/ formoterol studies $(0.4 \%-2.1 \%)$. These imbalances could plausibly have contributed to the exacerbation incidence differences observed. However, of all Cochrane studies, only Busse's and Ilowite's were conducted at US sites alone where proportions of black patients are likely to be higher than in multinational or European studies. Furthermore, even with enrollment of approximately $8 \%-14 \%$ black patients in Busse and Ilowite's studies, any increase in exacerbation incidence in the overall population would be expected to be modest based on the reported occurrence of exacerbations in long-term studies of African American asthmatics. ${ }^{(52-54)}$ As such, any inflation of overall exacerbation incidence differences between fluticasone/formoterol and other treatments in our review is likely to be very limited.

Concomitant use of other anti-asthma therapies was also reviewed, given the potential for add-on medications to further reduce the occurrence of exacerbations. Although use of other asthma medications was permitted by Price et al., Fitzgerald et al., and Aubier et al., none allowed the concomitant use of leukotriene modifiers and, whilst two studies $^{(39,44)}$ permitted the use of anticholinergics, long- 
acting antimuscarinics do not appear to have been employed. Thus, there appear to be no important differences in allowed concomitant asthma medications between any of the trials reviewed.

Trial duration was examined as exacerbation incidence inevitably increases with time and because a reduced frequency of asthma exacerbations is seen in the summer months. ${ }^{(55,56)}$ Study 1 was of 14 months duration, and in Study 2 approximately $46 \%$ of patients were allocated to 12 months treatment (the remainder were treated for 6 months), ensuring exposure to annual peaks in exacerbation frequency for at least two-thirds of the 752 patients. In comparison, of the eleven published studies (excluding Price et al.), only OPTIMA and FACET were of 12 months duration and two others (Ilowite et al. and Bjermer et al.) approached 12 months duration (both 48 weeks). In these four studies, exacerbation incidences ranged from $14.2 \%$ to $29.5 \%$. The remaining seven published studies were all of 24 to 28 weeks duration. Thus, four of the six studies in which the highest occurrences of exacerbations were reported were of at least 48 weeks duration. Given that the high event incidence in one of the shorter studies (van der Molen et al.: 24 weeks) appears to have been driven by the institution of OCS based on PEFR criteria, the importance of duration to event incidence becomes even more evident. The low event incidence in the fluticasone/formoterol studies is perhaps surprising in view of these observations.

The devices and formulations employed were examined given the association of the fine particle fraction (FPF) with pulmonary drug deposition ${ }^{(57,58)}$ and clinical outcomes. ${ }^{(59)}$ In most Cochrane studies where specific devices/formulations were mandated, the Turbuhaler or Diskus/Accuhaler were used to administer dry powder formulations of budesonide/formoterol and fluticasone/salmeterol, respectively, or the corresponding monoproducts in combination. The FPFs (expressed as a percentage of nominal dose) of these products at relevant flow rates are approximately $20 \%-35 \%$ (Turbuhaler) and $15 \%-20 \%$ (Diskus). ${ }^{(60,61)}$ By comparison, the FPF of the fluticasone/formoterol HFA pMDI combination product is approximately $42 \% .^{(60)}$ Thus, resulting differences in lung dose could potentially be implicated in the lower exacerbation occurrence seen in the fluticasone/ formoterol studies.

In the two trials ${ }^{(36,37)}$ in which the budesonide/formoterol pMDI (FPF approximately $44 \%)^{(62)}$ and fluticasone/salmeterol pMDI (FPF approximately $30 \%-35 \%)^{(62,63)}$ were employed, both of which have higher FPFs than their respective DPI products, no appreciable reduction in exacerbation incidence versus the corresponding DPI trial data were seen. However, other pharmaceutical factors can influence drug delivery from $p M D I s$ and fast forceful plumes may increase impaction of drug in the throat thereby reducing lung deposition, negating any benefit of a high FPF. ${ }^{(64)}$

Fluticasone/formoterol pMDI has a slower, longer lasting, and gentler plume than that of fluticasone/salmeterol, ${ }^{(64)}$ which may plausibly be associated with in vivo differences in lung deposition and therefore also outcomes. No published plume data are available for budesonide/formoterol pMDI. Hence, the pharmaceutical characteristics of fluticasone/formoterol pMDI may have contributed to the exacerbation differences observed. However, given the clinical doseresponse for both $\mathrm{ICSs}^{(65-67)}$ and $\mathrm{LABAs}^{(68)}$ is relatively shallow, the apparent magnitude of exacerbation risk reduction with fluticasone/formoterol remains somewhat surprising.

Finally, treatment adherence was evaluated given its association with clinical outcomes. ${ }^{(69,70)}$ Adherence in the fluticasone/formoterol studies and the four Cochrane studies $^{(35-37,39)}$ (excluding Price et al.) for which data were available was uniformly high. Of note in Price et al.'s real world study, adherence (based on prescriptions issued) with LABA was only $46 \%$ and with ICS only $64 \%$. This low (but typically "real life") level of adherence is likely to be an important contributory factor to the much higher exacerbation incidence seen therein.

In summary, our review of studies suggested that the real world nature of Price et al.'s study, the institution of OCS in response to PEFR criteria by van der Molen et al., and the recruitment of all but the most recurrent exacerbators in FACET are likely to have contributed significantly to the high event occurrence subsequently seen in those studies. In the remaining nine Cochrane-reviewed studies (including 15 treatment arms), there were no compelling design, device/ formulation, population, or adherence-related characteristics to explain the considerably higher exacerbation incidence (in 13 of 15 treatment arms) than in both fluticasone/formoterol studies. Amongst these studies, no greater concordance was evident between the designs/populations of the fluticasone/formoterol studies and Aubier's and Fitzgerald's studies (in which low exacerbation incidences were seen), compared to the other studies reviewed.

We acknowledge the limitations of attempting to extricate and evaluate individual features of these studies from amongst several others. A further limitation of our review is that, despite all studies detailing exacerbation-related enrollment criteria, none detailed the actual prior annual exacerbation rates in the patients recruited. In addition, biomarker data, such as fractional exhaled nitric oxide (FeNO) and blood/sputum eosinophils, which have been shown to be predictive of exacerbation risk $^{(71,72)}$ and response to treatment, ${ }^{(73-75)}$ were also unavailable for review.

Despite the above limitations, the comparatively low exacerbation incidence in both fluticasone/formoterol studies remains somewhat surprising, even in view of the pharmaceutical characteristics of fluticasone/formoterol that may have contributed to our results; our review of Cochrane trials suggests an exacerbation incidence of $10 \%-15 \%$ to be more in keeping with expectations-assuming that all ICSs and LABAs have similar effects at an equipotent dose. However, a variety of recent data suggest that this may not be the case.

In their meta-analysis, Adams et al. ${ }^{(76)}$ compared fluticasone versus budesonide or beclometasone at a 1:2 (i.e., equipotent) dose ratio. The odds ratio for patients on fluticasone experiencing an OCS exacerbation, compared to those on budesonide or beclometasone was 0.74 (95\% CI: $0.53,1.03)$. The corresponding odds ratios for withdrawal due to exacerbation and withdrawal due to lack of efficacy were $0.77(0.54,1.10)$ and $0.59(0.33,1.07)$, respectively. Thus the odds of each event were between $26 \%$ to $41 \%$ lower with fluticasone versus budesonide/beclometasone and in all three cases approached significance suggesting a trend in favor of fluticasone. No other similarly comprehensive meta-analyses are available, and sample sizes in individual studies have to date been too small to determine 
whether the trends suggested by Adams et al.'s data are reproducible.

Pharmacological differences between ICSs may explain the trend in the meta-analysis by Adams et al. Fluticasone is considerably more lipophilic than budesonide and beclometasone. It therefore exhibits slower dissolution through the aqueous airways surface fluid layer, ${ }^{(77,78)}$ prolonged contact with the airway epithelium, greater tissue binding, ${ }^{(79)}$ and glucocorticoid receptor binding affinity ${ }^{(80)}$ (hence enhanced tissue retention). Nonetheless, budesonide undergoes intracellular conjugation with fatty acids ${ }^{(81)}$ that, post-absorption, might be expected to mitigate the lesser lipophilicity of the parent compound. Thus differences in intra-pulmonary metabolism between fluticasone versus budesonide and beclometasone may also be implicated in any clinical differences between these ICSs.

All are metabolized by the cytochrome P450 3A family, with CYP 3 A5 the predominant lung isoform. ${ }^{(82,83)} \mathrm{Im}$ portantly, the CYP 3A5 gene is polymorphic: only patients with at least one $3 \mathrm{~A} 5 * 1$ allele express large amounts of functional protein, with approximately $45 \%$ of African Americans, ${ }^{(84)} 23 \%-40 \%$ of Asians, ${ }^{(84)}$ and $5 \%-15 \%$ of Caucasians (one report suggests 30\%) expressing this allele. ${ }^{(85)}$ In these patients, metabolic differences between different ICSs may however be very relevant, and may contribute to observed differences in ICS efficacy. Fluticasone, but not budesonide or beclometasone, is an extremely efficient inactivator of CYP 3A5, thereby inhibiting its own pulmonary metabolism. ${ }^{\left({ }^{82}\right)}$ Conversely, budesonide and beclometasone induce CYP $3 \mathrm{~A} 5,{ }^{(86,87)}$ which may enhance their pulmonary degradation. Therefore, intrapulmonary metabolism of budesonide and beclometasone may plausibly contribute to corticosteroid resistance or insensitivity, observed in approximately $30 \%$ of asthmatics. ${ }^{(88,89)}$

Turning to the comparison of LABAs, meta-analyses requested by the US Food and Drug Administration revealed that, when fixed combination fluticasone/salmeterol was compared to fluticasone monotherapy, there was no difference in the occurrence of asthma-related hospitalizations (OR: 1.01 ; 95\% CI: $0.60,1.69),{ }^{(90)}$ whereas a $32 \%$ reduction in the odds of asthma-related hospitalization was seen when formoterol plus budesonide (as either a free or fixed combination) was compared to budesonide monotherapy (OR: 0.68 ; $95 \%$ CI: 0.47, 0.99). ${ }^{(91)}$

Mechanistic studies may explain the apparent difference in protection from exacerbations afforded by formoterol and salmeterol. Levels of pro-inflammatory cytokines, including IL- $1 \beta$ and $\mathrm{TNF} \alpha$, are increased in the airways of asthmatics, ${ }^{(92,93)}$ and impair the smooth muscle relaxant effects of LABAs. ${ }^{(94,95)}$ However, cytokines reduce the smooth muscle relaxation induced by salmeterol to a significantly greater extent $(40 \%)$ than that induced by formoterol $(16 \%){ }^{(96)}$ Furthermore, corticosteroid administration completely reverses the cytokine-induced inhibition of formoterol effect, but has no effect on the inhibition of salmeterol effect. ${ }^{(96)}$

These differential effects may result from differences in LABA molecular structure leading to different conformational states of the activated $\beta 2$-adrenoceptor, hence differential activation of stimulatory and inhibitory $G$ proteins (Gs and $\mathrm{Gi}$, respectively). ${ }^{(96)}$ It is plausible that salmeterol binding to the $\beta_{2}$-adrenoceptor activates $\mathrm{Gi}$ to a greater extent than formoterol, explaining both the lesser intrinsic efficacy of salmeterol, but also the non-reversal of cytokineinduced inhibition of salmeterol effect by corticosteroid, ${ }^{(96)}$ since the Gi $\alpha$ subunit is corticosteroid insensitive. ${ }^{(97)}$ Clinically therefore, salmeterol may be more vulnerable than formoterol to inhibition by pro-inflammatory cytokines, levels of which may be further increased during asthma exacerbations. ${ }^{(96)}$

A second potentially important difference between salmeterol and formoterol lies in their disposal from smooth muscle cells, and the effect of ICSs upon this disposal. The clearance of cationic drugs from airway smooth muscle cells is facilitated by cationic transporters, with organic cation transporter (OCT) 3 being the predominant species. ${ }^{(98)}$ OCT3 is inhibited by corticosteroids; ${ }^{(98)}$ thus ICS may inhibit the disposal of cationic formoterol from smooth muscle cells and thereby increase local tissue concentrations. This beneficial interaction is not seen for (lipophilic) salmeterol, as it is not a substrate for OCT3 and its disposal is not therefore slowed by corticosteroid co-administration. ${ }^{(98)}$

Finally, cAMP production induced by formoterol is resistant to oxidative stress, whereas that induced by salmeterol is not; ${ }^{(99)}$ furthermore, formoterol reverses corticosteroid insensitivity under conditions of oxidative stress whereas salmeterol does not. ${ }^{(99)}$ It is hypothesized that these differences are due to inhibition of $\mathrm{PI} 3 \mathrm{~K} \delta$ signalling by formoterol but not salmeterol. ${ }^{(99)}$ Thus, formoterol may confer greater clinical benefit than salmeterol under oxidative stress, for example in severe asthmatics or in asthmatic smokers.

In conclusion, a low incidence of exacerbations was seen in two fixed dose fluticasone/formoterol studies, which was considerably lower than in the majority of comparable published studies involving other combinations of ICS/ LABAs. Whilst recognizing the limitations of this cross-trial comparison, it is plausible that the low event incidence with fluticasone/formoterol is related to each of its constituent components exhibiting favorable characteristics compared to other widely used drugs in their respective classes. Further head-to-head studies comparing fluticasone/formoterol to other ICS/LABAs are warranted to ascertain whether the observations in this cross-trial setting can be replicated.

\section{Acknowledgments}

The two long-term studies of fluticasone/formoterol presented here were sponsored by Skyepharma AG. Writing assistance in the preparation of this manuscript was provided by Ms. Karen Mower of Scientific Editorial. Mundipharma Research Limited provided financial support for the preparation of the manuscript, including all article processing charges. All named authors meet the ICMJE criteria for authorship for this manuscript, have been involved in the analysis and interpretation of the data, the writing and review of the manuscript, in the decision to submit the manuscript for publication, and have given final approval of the version to be published.

( ${ }^{\circ}$ FLUTIFORM is a registered trade mark of Jagotec AG and is used under license.

\section{Author Disclosure Statement}

Professor Alberto Papi has been on Scientific Advisory Boards, and has received grants and speaker fees from 
Mundipharma. Dr. Adel Mansur was Chief Investigator for Study 2; has contributed to paid advisory board meetings, received sponsorships to attend respiratory conferences and payment for talks by various pharmaceutical companies that include GlaxoSmithKline, AstraZeneca, Napp Pharmaceuticals Limitedd, Novartis, Roche, Boehringer Ingelheim, and Aerocrinewas. Professor Tetyana Pertseva was an Investigator for Study 1. Dr Kirsten Kaiser is an employee of Skyepharma AG; Mrs Tammy McIver, Ms Birgit Grothe, and Dr Sanjeeva Dissanayake are employees of Mundipharma Research Limited.

Funding sources: The two long-term studies of fluticasone propionate/formoterol were sponsored by Skyepharma AG. Mundipharma Research Limited provided financial support for the preparation of the manuscript, including all article processing charges.

\section{References}

1. Reddel HK, Taylor DR, Bateman ED, Boulet LP, Boushey HA, Busse WW, Casale TB, Chanez P, Enright PL, Gibson PG, de Jongste JC, Kerstjens HA, Lazarus SC, Levy ML, O'Byrne PM, Partridge MR, Pavord ID, Sears MR, Sterk PJ, Stoloff SW, Sullivan SD, Szefler SJ, Thomas MD, and Wenzel SE; American Thoracic Society/European Respiratory Society Task Force on Asthma Control and Exacerbations: An official American Thoracic Society/ European Respiratory Society statement: Asthma control and exacerbations: Standardizing endpoints for clinical asthma trials and clinical practice. Am J Respir Crit Care Med. 2009;180:59-99.

2. GINA Report, Global Strategy for Asthma Management and Prevention. Available from: http://www.ginasthma.org/local/ uploads/files/GINA_Report_2014_Aug12.pdf. Accessed on December 17, 2014.

3. Li D, German D, Lulla S, Thomas RG, and Wilson SR: Prospective study of hospitalization for asthma. A preliminary risk factor model. Am J Respir Crit Care Med. 1995; 151:647-655.

4. Schatz M, Zeiger RS, Yang SJ, Chen W, Crawford W, Sajjan S, and Allen-Ramey F: The relationship of asthma impairment determined by psychometric tools to future asthma exacerbations. Chest. 2012;141:66-72.

5. Ko FW, Hui DS, Leung TF, Chu HY, Wong GW, Tung AH, Ngai JC, Ng SS, and Lai CK: Evaluation of the asthma control test: A reliable determinant of disease stability and a predictor of future exacerbations. Respirology. 2012;17: 370-378.

6. Suissa S, Ernst P, and Kezouh A: Regular use of inhaled corticosteroids and the long term prevention of hospitalisation for asthma. Thorax. 2002;57:880-884.

7. Ulrik CS, and Frederiksen J: Mortality and markers of risk of asthma death among 1,075 outpatients with asthma. Chest. 1995;108:10-15.

8. Osborne ML, Pedula KL, O'Hollaren M, Ettinger KM, Stibolt T, Buist AS, and Vollmer WM: Assessing future need for acute care in adult asthmatics: The Profile of Asthma Risk Study: A prospective health maintenance organization-based study. Chest. 2007;132:1151-1161.

9. Kitch BT, Paltiel AD, Kuntz KM, Dockery DW, Schouten JP, Weiss ST, and Fuhlbridgge AL: A single measure of FEV1 is associated with risk of asthma attacks in long-term follow-up. Chest. 2004;126:1875-1882.
10. Price D, Zhang Q, Kocevar VS, Yin DD, and Thomas M: Effect of a concomitant diagnosis of allergic rhinitis on asthma-related health care use by adults. Clin Exp Allergy. 2005;35:282-287.

11. Thomas M, Kocevar VS, Zhang Q, Yin DD, and Price D: Asthma-related health care resource among asthmatic children with and without concomitant allegic rhinitis. Pediatrics. 2005;115:129-134.

12. Bahadori K, Doyle-Waters MM, Marra C, Lynd L, Alasaly K, Swiston J, and FitzGerald JM: Economic burden of asthma: A systematic review. BMC Pulm Med. 2009; 9:24.

13. Accordini S, Bugiani M, Arossa W, Gerzeli S, Marinoni A, Olivieri M, Pirina P, Carrozzi L, Dallari R, De Togni A, and de Marco R: Poor control increases the economic cost of asthma. A multicentre population-based study. Int Arch Allergy Immunol. 2006;141:189-198.

14. Hoskins G, McCowan C, Neville RG, Thomas GE, Smith B, and Silverman S: Risk factors and costs associated with an asthma attack. Thorax. 2000;55:19-24.

15. Fuhlbrigge A, Peden D, Apter AJ, Boushey HA, Camargo CA Jr, Gern J, Heymann PW, Martinez FD, Mauger D, Teague WG, and Blaisdell C: Asthma outcomes: Exacerbations. J Allergy Clin Immunol. 2012;129:S34-48.

16. Pauwels RA, Löfdahl CG, Postma DS, Tattersfield AE, O'Byrne P, Barnes PJ, and Ullman A, for the Formoterol and Corticosteroids Establishing Therapy (FACET) International Study Group: Effect of inhaled formoterol and budesonide on exacerbations of asthma. N Engl J Med. 1997;337:1405-1411.

17. Ind PW, Dal Negro R, Colman NC, Fletcher CP, Browning $\mathrm{D}$, and James MH: Addition of salmeterol to fluticasone propionate treatment in moderate-to-severe asthma. Respir Med. 2003;97:555-562.

18. O’Byrne PM, Barnes PJ, Rodriguez-Roisin R, Runnerstrom E, Sandstrom T, Svensson K, and Tattersfield A: Low dose inhaled budesonide and formoterol in mild persistent asthma: The OPTIMA randomized trial. Am J Respir Crit Care Med. 2001;168:1392-1397.

19. O'Byrne PM, Bisgaard H, Godard PP, Pistolesi M, Palmqvist M, Zhu Y, Ekström T, and Bateman ED: Budesonide/formoterol combination therapy as both maintenance and reliever medication in asthma. Am J Respir Crit Care Med. 2005;171:129-136.

20. Verona E, Petrov D, Cserhati E, Hofman J, Geppe N, Medley $\mathrm{H}$, and Hughes S: Fluticasone propionate in asthma: A long term dose comparison study. Arch Dis Child. 2003;88:503-509.

21. Bateman ED, Boushey HA, Bousquet J, Busse WW, Clark TJ, Pauwels RA, and Pedersen SE; GOAL Investigators Group: Can guideline-defined asthma control be achieved? The Gaining Optimal Asthma ControL study. Am J Respir Crit Care Med. 2004;170:836-844.

22. Ducharme FM, Ni Chroinin M, Greenstone I, and Lasserson TJ: Addition of long-acting beta2-agonists to inhaled steroids versus higher dose inhaled steroids in adults and children with persistent asthma. Cochrane Database Syst Rev. 2010, Issue 4. DOI: 10.1002/14651858 .CD005533.

23. Bodzenta-Lukaszyk A, Buhl R, Balint B, Lomax M, Spooner $\mathrm{K}$, and Dissanayake S: Fluticasone/formoterol combination therapy versus budesonide/formoterol for the treatment of asthma: A randomized, controlled, non-inferiority trial of efficacy and safety. J Asthma. 2012;49:1060-1070. 
24. Aalbers R, Brusselle G, McIver T, Grothe B, and BodzentaLukaszyk A: Onset of bronchodilation with fluticasone/formoterol combination versus fluticasone/salmeterol in an open-label, randomized study. Adv Ther. 2012;29:958-969.

25. Bodzenta-Lukaszyk A, Dymek A, McAulay K, and Mansikka H: Fluticasone/formoterol combination therapy is as effective as fluticasone/salmeterol in the treatment of asthma, but has a more rapid onset of action: An openlabel, randomized study. BMC Pulm Med. 2011;11:28.

26. Bodzenta-Lukaszyk A, Pulka G, Dymek A, Bumbacea D, McIver T, Schwab B, and Mansikka H: Efficacy and safety of fluticasone and formoterol in a single pressurized metered dose inhaler. Respir Med. 2011;105:674-682.

27. Corren J, Mansfield LE, Pertseva T, Blahzko V, and Kaiser $\mathrm{K}$ : Efficacy and safety of fluticasone/formoterol combination therapy in patients with moderate-to-severe asthma. Respir Med. 2013;107:180-195.

28. Nathan RA, D’Urzo A, Blazhko V, and Kaiser K: Safety and efficacy of fluticasone/formoterol combination therapy in adolescent and adult patients with mild-to-moderate asthma: A randomised controlled trial. BMC Pulm Med. 2012;12:67.

29. Bodzenta-Lukaszyk A, van Noord J, Schroder-Babo W, McAulay K, and McIver T: Efficacy and safety profile of fluticasone/formoterol combination therapy compared to its individual components administered concurrently in asthma: A randomised controlled trial. Curr Med Res Opin. 2013;29:579-588.

30. Kaiser K. and Pertseva T: Long-term safety and efficacy of fluticasone propionate/formoterol fumarate combination therapy in patients with asthma. Prim Care Respir J. 2013; 22:A1-A18.

31. Mansur AH, and Kaiser K: Long-term safety and efficacy of fluticasone/formoterol combination therapy in asthma. J Aerosol Med Pulm Drug Deliv. 2013;26:190-199.

32. Lasserson TJ, Ferrara G, and Casali L: Combination fluticasone and salmeterol versus fixed dose combination budesonide and formoterol for chronic asthma in adults and children. Cochrane Database Syst Rev. 2011, Issue 12. DOI: 10.1002/14651858. CD004106.

33. Chauhan BF, and Ducharme FM: Addition to inhaled corticosteroids of long-acting beta2 agonists versus antileukotrienes for chronic asthma. Cochrane Database Syst Rev. 2014, Issue 1. DOI: 10.1002/14651858.CD003137.pub5.

34. Pertseva T, Dissanayake S, and Kaiser K: Superiority of fluticasone propionate/formoterol fumarate versus fluticasone propionate alone in patients with moderate-to-severe asthma: a randomised controlled trial. Curr Med Res Opin. 2013;29:1357-1369.

35. Aalbers R, Backer V, Kava TT, Omenaas ER, Sandström T, Jorup C, and Welte T: Adjustable maintenance dosing with budesonide/formoterol compared with fixed-dose salmeterol/fluticasone in moderate to severe asthma. Curr Med Res Opin. 2004;20:225-240.

36. Busse WW, Shah SR, Somerville L, Parasuraman B, Martin $\mathrm{P}$, and Goldman M: Comparison of adjustable- and fixeddose budesonide/formoterol pressurized metered-dose inhaler and fixed-dose fluticasone propionate/salmeterol dry powder inhaler in asthma patients. J Allergy Clin Immunol. 2008;121:1407-1414.

37. Kuna P, Peters MJ, Manjra AI, Jorup C, Naya IP, MartinezJimenez NE, and Buhl R: Effect of budesonide/formoterol maintenance and reliever therapy on asthma exacerbations. Int J Clin Pract. 2007;61:725-736.
38. Dahl R, Chuchalin A, Gor D, Yoxall S, and Sharma R: EXCEL: A randomised trial comparing salmeterol/fluticasone propionate and formoterol/budesonide combinations in adults with persistent asthma. Respir Med. 2006;100: 1152-1162.

39. Aubier M, Pieters WR, Schlosser NJ, and Steinmetz KO: Salmeterol/fluticasone propionate $(50 / 500 \mu \mathrm{g})$ in combination in a Diskus ${ }^{\circledR}$ inhaler (Seretide ${ }^{\circledR}$ ) is effective and safe in the treatment of steroid-dependent asthma. Respir Med. 1999;93:876-884.

40. Fitzgerald JM, Chapman KR, Della Cioppa G, Stubbing D, Fairbarn MS, Till MD, and Brambilla R: Sustained bronchoprotection, bronchodilatation, and symptom control during regular formoterol use in asthma of moderate or greater severity. The Canadian FO/OD1 Study Group. J Allergy Clin Immunol. 1999;103:427-435.

41. van der Molen T, Postma DS, Turner MO, Jong BM, Malo JL, Chapman K, Grossman R, de Graaff CS, Riemersma RA, and Sears MR: Effects of the long acting beta agonist formoterol on asthma control in asthmatic patients using inhaled corticosteroids. The Netherlands and Canadian Formoterol Study Investigators. Thorax. 1997;52: 535-539.

42. Bjermer L, Bisgaard H, Bousquet J, Fabbri LM, Greening AP, Haahtela T, Holgate ST, Picado C, Menten J, Dass SB, Leff JA, and Polos PG: Montelukast and fluticasone compared with salmeterol and fluticasone in protecting against asthma exacerbation in adults: One year, double blind, randomised, comparative trial. BMJ. 2003;327: 891.

43. Ilowite J, Webb R, Friedman B, Kerwin E, Bird SR, Hustad CM, and Edelman JM: Addition of montelukast or salmeterol to fluticasone for protection against asthma attacks: a randomized, double-blind, multicenter study. Ann Allergy Asthma Immunol. 2004;92:641-648.

44. Price D, Musgrave SD, Shepstone L, Hillyer EV, Sims EJ, Gilbert RFT, Juniper EF, Ayres JG, Kemp L, Blyth A, Wilson EC, Wolfe S, Freeman D, Mugford HM, Mudoch J, and Harvey I: Leukotriene antagonists as first-line or addon asthma-controller therapy. N Engl J Med. 2011;364: 1695-1707.

45. Zeiger RS, Yegin A, Simons FE, Haselkorn T, Rasouliyan L, Szefler SJ, and Chipps BE; TENOR Study Group: Evaluation of the National Heart, Lung, and Blood Institute guidelines impairment domain for classifying asthma control and predicting asthma exacerbations. Ann Allergy Asthma Immunol. 2012;108:81-87.

46. Hurst JR, Donaldson GC, Quint JK, Goldring JJ, BaghaiRavary R, and Wedzicha JA: Temporal clustering of exacerbations in chronic obstructive pulmonary disease. Am J Respir Crit Care Med. 2009;179:369-374

47. Tattersfield AE, Postma DS, Barnes PJ, Svensson K, Bauer C-A, O'Byrne PM, Löfdahl CG, Pauwels RA, and Ullman A: Exacerbations of asthma: A descriptive study of 425 severe exacerbations. Am J Respir Crit Care Med. 1999; 160:594-599.

48. Vogelmeier C, Hederer B, Glaab T, Schmidt H, Rutten-van Mölken MP, Beeh KM, Rabe KF, and Fabbri LM; POETCOPD Investigators: Tiotropium versus salmeterol for the prevention of exacerbations of COPD. $\mathrm{N}$ Engl $\mathrm{J}$ Med. 2011;364:1093-1103.

49. Koga T, Oshita Y, Kamimura T, Koga H, and Aizawa H: Characterisation of patients with frequent exacerbation of asthma. Respir Med. 2006;100:273-278. 
50. Williams LK, Peterson EL, Wells K, Ahmedani BK, Kumar R, Burchard EG, Chowdhry VK, Favro D, Lanfear DE, and Pladevall M. Quantifying the proportion of severe asthma exacerbations attributable to inhaled corticosteroid nonadherence. J Allergy Clin Immunol. 2011;128:1185-1191.

51. Shalowitz MU, Sadowski LM, Kumar R, Weiss KB, and Shannon JJ. Asthma burden in a citywide, diverse sample of elementary schoolchildren in Chicago. Ambul Pediatr. 2007;7:271-277.

52. Bailey W, Castro M, Matz J, White M, Dransfield M, Yancey S, and Ortega H. Asthma exacerbations in African Americans treated for 1 year with combination fluticasone propionate and salmeterol or fluticasone propionate alone. Curr Med Res Opin. 2008;24:1669-1682.

53. Brown RW, O'Brien CD, Martin UJ, Uryniak T, and Lampl KL. Long-term safety and asthma control measures with a budesonide/formoterol pressurized metered-dose inhaler in African American asthmatic patients: A randomized controlled trial. J Allergy Clin Immunol. 2012;130:362-367.

54. Wechsler ME, Yawn BP, Fuhlbrigge AL, Pace WD, Pencina MJ, Doros G, Kazani S, Raby BA, Lanzillotti J, Madison S, and Israel E; BELT Investigators. Anticholinergic vs long-acting $\beta$-agonist in combination with inhaled corticosteroids in black adults with asthma: The BELT Randomized Clinical Trial. JAMA. 2015;314:1720-1730.

55. Johnston NW, and Sears MR: Asthma exacerbations. 1: Epidemiology. Thorax. 2006;61:722-728.

56. Covar RA, Szefler SJ, Zeiger RS, Sorkness CA, Moss M, Mauger DT, Boehmer SJ, Strunk RC, Martinez FD, and Taussig LM: Factors associated with asthma exacerbations during a long-term clinical trial of controller medications in children. J Allergy Clin Immunol. 2008;122:741-747.

57. Van Holsbeke C, Marshall J, De Backer J, and Vos W. Median mass aerodynamic diameter (MMAD) and fine particle fraction (FPF): Influence on lung deposition? Eur Respir J. 2014;44:S58.

58. Newman SP, and Pitcairn GR. In vitro/in vivo correlations for respiratory drug delivery. Clin Res Reg Affairs. 2005; 22:15-30.

59. Richardson $\mathrm{CH}$, de Matas $\mathrm{M}$, Hosker $\mathrm{H}$, Mukherjee R, Wong I, and Chrystyn H. Determination of the relative bioavailability of salbutamol to the lungs following inhalation from dry powder inhaler formulations containing drug substance manufactured by supercritical fluids and micronization. Pharm Res. 2007;24:2008-2017.

60. Johal B, Howald M, Fischer M, Marshall J, and Venthoye G. Fine particle profile of fluticasone propionate/formoterol fumarate versus other combination products: The DIFFUSE study. Comb Prod Ther. 2013;3:39-51.

61. Kamin WE, Genz T, Roeder S, Scheuch G, Trammer T, Juenemann R, and Cloes RM. Mass output and particle size distribution of glucocorticosteroids emitted from different inhalation devices depending on various inspiratory parameters. J Aerosol Med. 2002;15:65-73.

62. Mitchell JP, Nagel MW, MacKay HA, Avvakoumova VI, and Malpass J. Developing a universal Valved Holding Chamber (VHC) platform with added patient benefits whilst maintaining consistent in vitro performance. RDD Europe. 2009;2:383-386.

63. Nagel MW, Wiersema KJ, Bates SL, and Mitchell JP. Performance of large- and small-volume valved holding chambers with a new combination long-term bronchodilator/ anti-inflammatory formulation delivered by pressurized metered dose inhaler. J Aerosol Med. 2002;15:427-433.
64. Johal B, Murphy S, Tuohy J, and Marshall J. Plume characteristics of two HFA-driven corticosteroid/long-acting beta2-agonist combination pressurised metered-dose inhalers. Adv Ther. 2015;32:567-579.

65. Adams N, Bestall J, and Jones P. Beclomethasone at different doses for chronic asthma (review). Cochrane Database Syst Rev. 1999;CD002879.

66. Adams N, Bestall J, and Jones PW. Budesonide at different doses for chronic asthma. Cochrane Database Syst Rev. 2000;CD003271.

67. Adams NP, Bestall JC, Jones P, Lasserson TJ, Griffiths B, and Cates CJ. Fluticasone at different doses for chronic asthma in adults and children. Cochrane Database Syst Rev. 2008;CD003534.

68. Wolfe J, Laforce C, Friedman B, Sokol W, Till D, Della Cioppa G, and van As A. Formoterol, 24 microg bid, and serious asthma exacerbations: Similar rates compared with formoterol, 12 microg bid, with and without extra doses taken on demand, and placebo. Chest. 2006;129:27-38.

69. Small M, Anderson P, Vickers A, Kay S, and Fermer S. Importance of inhaler-device satisfaction in asthma treatment: Real-world observations of physician-observed compliance and clinical/patient-reported outcomes. Adv Ther. 2011;28:202-212.

70. Mäkelä MJ, Backer V, Hedegaard M, and Larsson K. Adherence to inhaled therapies, health outcomes and costs in patients with asthma and COPD. Respir Med. 2013;107: 1481-1490.

71. Green RH, Brightling CE, McKenna S, Hargadon B, Parker D, Bradding P, Wardlaw AJ, and Pavord ID: Asthma exacerbations and sputum eosinophil counts: A randomised controlled trial. Lancet. 2002;360:1715-1721.

72. Jayaram L, Pizzichini MM, Cook RJ, Boulet LP, Lemière C, Pizzichini E, Cartier A, Hussack P, Goldsmith CH, Laviolette M, Parameswaran K, and Hargreave FE: Determining asthma treatment by monitoring sputum cell counts: Effect on exacerbations. Eur Respir J. 2006;27:483-494.

73. Pavord ID, Korn S, Howarth P, Bleecker ER, Buhl R, Keene $\mathrm{ON}$, Ortega $\mathrm{H}$, and Chanez P: Mepolizumab for severe eosinophilic asthma (DREAM): A multicentre, double-blind, placebo-controlled trial. Lancet. 2012;380:651-659.

74. Hanania NA, Wenzel S, Rosén K, Hsieh HJ, Mosesova S, Choy DF, Lal P, Arron JR, Harris JM, and Busse W: Exploring the effects of omalizumab in allergic asthma: An analysis of biomarkers in the EXTRA study. Am J Respir Crit Care Med. 2013;187:804-811.

75. Pettipher R, Hunter MG, Perkins CM, Collins LP, Lewis T, Baillet M, Steiner J, Bell J, and Payton MA: Heightened response of eosinophilic asthmatic patients to the CRTH2 antagonist OC000459. Allergy. 2014;69:1223-1232.

76. Adams N, Lasserson TJ, Cates CJ, and Jones PW: Fluticasone versus beclomethasone or budesonide for chronic asthma in adults and children. Cochrane Database Syst Rev. 2007;CD002310.

77. Thorsson L, Edsbäcker S, Källén A, and Löfdahl CG: Pharmacokinetics and systemic activity of fluticasone via Diskus and pMDI, and of budesonide via Turbuhaler. Br J Clin Pharmacol. 2001;52:529-538.

78. Möllmann H, Wagner M, Meibohm B, Hochhaus G, Barth J, Stöckmann R, Krieg M, Weisser H, Falcoz C, and Derendorf $\mathrm{H}$ : Pharmacokinetic and pharmacodynamic evaluation of fluticasone propionate after inhaled administration. Eur J Clin Pharmacol. 1998;53:459-467. 
79. Esmailpour N, Högger P, and Rohdewald P: Binding of glucocorticoids to human nasal tissue in vitro. Int Arch Allergy Immunol. 2000;122:151-154.

80. Baumann D, Bachert C, and Högger P: Dissolution in nasal fluid, retention and anti-inflammatory activity of fluticasone furoate in human nasal tissue ex vivo. Clin Exp Allergy. 2009;39:1540-1550.

81. Nave R, Fisher R, and McCracken N: In vitro metabolism of beclomethasone dipropionate, budesonide, ciclesonide, and fluticasone propionate in human lung precision-cut tissue slices. Respir Res. 2007;8:65.

82. Moore CD, Roberts JK, Orton CR, Murai T, Fidler TP, Reilly CA, Ward RM, and Yost GS: Metabolic pathways of inhaled glucocorticoids by the CYP3A enzymes. Drug Metab Dispos. 2013;41:379-389.

83. Murai T, Reilly CA, Ward RM, and Yost GS: The inhaled glucocorticoid fluticasone propionate efficiently inactivates cytochrome P450 3A5, a predominant lung P450 enzyme. Chem Res Toxicol. 2010;23:1356-1364.

84. Daly AK: Significance of the minor cytochrome P450 3A isoforms. Clin Pharmacokinet. 2006;45:13-31.

85. Kuehl P, Zhang J, Lin Y, Lamba J, Assem M, Schuetz J, Watkins PB, Daly A, Wrighton SA, Hall SD, Maurel P, Relling M, Brimer C, Yasuda K, Venkataramanan R, Strom S, Thummel K, Boguski MS, and Schuetz E: Sequence diversity in CYP3A promoters and characterization of the genetic basis of polymorphic CYP3A5 expression. Nat Genet. 2001;27:383-391.

86. Roberts JK, Moore CD, Ward RM, Yost GS, and Reilly CA: Metabolism of beclomethasone dipropionate by cytochrome P4503A enzymes. J Pharmacol Exp Ther. 2013;345:308-316.

87. Hukkanen J, Väisänen T, Lassila A, Piipari R, Anttila S, and Pelkonen O: Regulation of CYP3A5 by glucocorticoids and cigarette smoke in human lung-derived cells. J Pharmacol Exp Ther. 2003;304:745-752.

88. Chan MT, Leung DY, Szefler SJ, and Spahn JD: Difficult-tocontrol asthma: Clinical characteristics of steroid-insensitive asthma. J Allergy Clin Immunol. 1998;101:594-601.

89. Szefler SJ, Martin RJ, King TS, Boushey HA, Cherniack RM, Chinchilli VM, Craig TJ, Dolovich M, Drazen JM, Fagan JK, Fahy JV, Fish JE, Ford JG, Israel E, Kiley J, Kraft M, Lazarus SC, Lemanske RF Jr, Mauger E, Peters SP, and Sorkness CA; Asthma Clinical Research Network of the National Heart, Lung, and Blood Institute: Significant variability in response to inhaled corticosteroids for persistent asthma. J Allergy Clin Immunol. 2002;109:410-418.

90. GlaxoSmithKline Briefing Document. [December 10-11, 2008]. Benefit risk assessment of salmeterol for the treatment of asthma in adults and children. www.fda.gov/ ohrms/dockets/ac/08/briefing/2008-4398b1-04-GSK.pdf. Accessed October 29, 2014.

91. AstraZeneca Briefing Document. [November 3, 2008] Review of the benefits and risks of formoterol-containing products. www.fda.gov/ohrms/dockets/ac/08/briefing/2008-
4398b1-03-AstraZeneca.pdfwww.fda.gov/ohrms/dockets/ ac/08/briefing/2008-4398b1-03-AstraZeneca.pdf. Accessed October 29, 2014.

92. Broide DH, Lotz M, Cuomo AJ, Coburn DA, Federman EC, and Wasserman SI: Cytokines in symptomatic asthma airways. J Allergy Clin Immunol. 1992;89:958-967.

93. Tonnel AB, Gosset P, and Tillie-Leblond I: Characteristics of the inflammatory response in bronchial lavage fluids from patients with status asthmaticus. Int Arch Allergy Immunol. 2001;124:267-271.

94. Hakonarson H, Herrick DJ, Serrano PG, and Grunstein MM: Mechanism of cytokine-induced modulation of betaadrenoceptor responsiveness in airway smooth muscle. J Clin Invest. 1996;97:2593-2600.

95. Wills-Karp M, Uchida Y, Lee JY, Jinot J, Hirata A, and Hirata F: Organ culture with proinflammatory cytokines reproduces impairment of the beta-adrenoceptor-mediated relaxation in tracheas of a guinea pig antigen model. Am J Respir Cell Mol Biol. 1993;8:153-159.

96. Adner M, Larsson B, Säfholm J, Naya I, and MillerLarsson A: Budesonide prevents cytokine-induced decrease of the relaxant responses to formoterol and terbutaline, but not to salmeterol, in mouse trachea. J Pharmacol Exp Ther. 2010;333:273-280.

97. Kalavantavanich K and Schramm CM: Dexamethasone potentiates high affinity beta-agonist binding and g(s)alpha protein expression in airway smooth muscle. Am J Physiol Lung Cell Mol Physiol. 2000;278:L1101-L1106.

98. Horvath G, Schmid N, Fragoso MA, Schmid A, Conner GE, Salathe M, and Wanner A: Epithelial organic cation transporters ensure $\mathrm{pH}$ dependent drug absorption in the airway. Am J Respir Cell Mol Biol. 2007;36:53-60.

99. Rossios C, To Y, Osoata G, Ito M, Barnes PJ, and Ito K: Corticosteroid insensitivity is reversed by formoterol via phosphoinositide-3-kinase inhibition. Br J Pharmacol. 2012; 167:775-786.

Received on August 6, 2015 in final form, January 21, 2016

Reviewed by:

Paula Anderson Federico Lavorini

Address correspondence to: Professor Alberto Papi Research Centre on Asthma and COPD University of Ferrara

Via Savonarola 9 44121 Ferrara Italy

E-mail: ppa@unife.it 